\title{
An evaluation survey of traditional Chinese medicine learning among international students majoring in conventional medicine: a study from a university in China
}

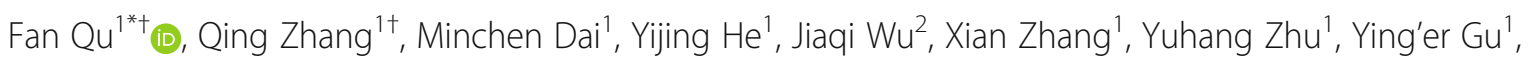
Fangfang Wang ${ }^{1}$ and Xiangrong $\mathrm{Xu}^{1}$

\begin{abstract}
Background: Traditional Chinese medicine (TCM) has gained increasing acceptance and popularity by the global community. The current study aimed to investigate self-reported evaluations of learning TCM and opinions about TCM courses among undergraduate international students majoring in conventional medicine at a university in China.

Methods: A cross-sectional survey was conducted at the Zhejiang University School of Medicine. A self-reported questionnaire was administered to international undergraduates who were enrolled in the TCM course during the 2018 and 2019 academic years $(n=157)$. The course employed a student-centered, multiform learning model. Demographic data and self-reported evaluations of TCM learning background and TCM learning course were obtained to conduct the analysis.
\end{abstract}

Results: A total of 133 students responded to the questionnaire. Among the respondents, 21.0\% had some TCMrelated knowledge, and $51.1 \%$ were interested in learning TCM before the course. Ninety-six students (85.7\%) were from Asia. Students from Thailand showed significantly more interest in learning TCM than did students from other Asian countries $(p=0.025)$. After the course, $77.2 \%$ of students agreed that the course had brought about many benefits, $86.4 \%$ were satisfied with the course content, and $77.3 \%$ were satisfied with the teaching method. Students expressed their willingness to further learn acupuncture and to obtain more skilled practice through more visualized learning methods.

Conclusions: The majority of the international students we surveyed agreed that the TCM course improved their interest in and understanding of TCM. It is thus suggested that TCM education should be directed toward students' learning barriers and needs.

Keywords: Traditional Chinese medicine, Education, International undergraduates, Cross-sectional survey

\footnotetext{
* Correspondence: syqufan@zju.edu.cn

${ }^{\dagger}$ Fan Qu and Qing Zhang contributed equally to this work.

'Women's Hospital, School of Medicine, Zhejiang University, 1 Xueshi Road, Hangzhou 310006, Zhejiang, China

Full list of author information is available at the end of the article
}

(c) The Author(s). 2020 Open Access This article is licensed under a Creative Commons Attribution 4.0 International License, which permits use, sharing, adaptation, distribution and reproduction in any medium or format, as long as you give appropriate credit to the original author(s) and the source, provide a link to the Creative Commons licence, and indicate if changes were made. The images or other third party material in this article are included in the article's Creative Commons licence, unless indicated otherwise in a credit line to the material. If material is not included in the article's Creative Commons licence and your intended use is not permitted by statutory regulation or exceeds the permitted use, you will need to obtain permission directly from the copyright holder. To view a copy of this licence, visit http://creativecommons.org/licenses/by/4.0/ The Creative Commons Public Domain Dedication waiver (http://creativecommons.org/publicdomain/zero/1.0/) applies to the data made available in this article, unless otherwise stated in a credit line to the data. 


\section{Background}

Traditional Chinese medicine (TCM) education is an important component of biomedical education in China [1]. The Chinese Ministry of Health stipulates that undergraduate medical universities must provide nationally standardized courses in TCM [2, 3]. In China, undergraduate curricula for TCM education cover fundamental courses in Chinese medicine, including the classics of TCM, fundamental courses of acupuncture and moxibustion, clinical practice, etc. [4]. Unlike modern biomedical healthcare, TCM has a unique philosophical foundation and a holistic system of theories and practices [5], which make the TCM curriculum important but challenging. In recent years, TCM has been making its way to many countries worldwide, and related higher education programs have been developed in various modes in different countries, which reflect national policies, acceptance and popularity toward TCM [4-8].

With many international students coming to China to learn medicine, Chinese medical institutions have attached importance to the internationalization of their education system. There are 52 medical schools that offer an English Bachelor of Medicine and Surgery degree, which is a medical education program specifically designed for international students who wish to pursue a medical bachelor's degree in China $[9,10]$. The internationalization trend of medical education undoubtedly affects the global nature of medical curricula and, more importantly, promotes idea exchanges between different cultures [9]. However, TCM education for international students is a challenging task for universities and teachers, especially for those responsible for TCM curricula in Western medical universities or schools. Differences in cultural backgrounds and teaching approaches, gaps in language, insufficient professionals and teaching materials, and the lack of communication tools and opportunities are the main barriers to international students understanding the abstract and obscure theories of TCM [11]. Moreover, the lack of a sufficient learning atmosphere and enthusiasm for TCM, preconceived notions of conventional medicine, limited didactic hours and insufficient skills practice are general problems related to TCM education in medical universities or schools [12].

Zhejiang University is one of China's higher education institutions. It currently ranks among the top 10 universities on the Chinese mainland [13] and within the top 100 universities in the QS World University Rankings 2020 [14]. A total of more than 6300 students, including a cohort of 600 international students, are currently studying with its faculty of medicine, i.e., the Zhejiang University School of Medicine (ZUSM) [15]. The course titled "Basic Traditional Chinese Medicine" has been set up in ZUSM as one of the curriculum requirements of the Medical Bachelor, Bachelor of Surgery (MBBS) program [10]. All undergraduate international students in ZUSM major in conventional medicine, and the TCM course is a component of their program system. Since the 2018 academic year, the course has employed student-centered, multiform teaching methods. In this study, a questionnaire was used to investigate selfreported evaluations of learning TCM and opinions about TCM courses among undergraduate international students in ZUSM.

\section{Methods}

\section{Study design and setting}

The cross-sectional survey was conducted at Zhejiang University, Hangzhou, China. In the 2018-2019 academic year, the course titled "Basic Traditional Chinese Medicine" was reformed from the traditional teachercentered lecture-based learning (LBL) method to a student-centered, multiform learning model. The general objective of this course is to introduce the fundamental theories and skills practice of TCM to undergraduate international students.

\section{Participants}

Two consecutive cohorts of students attending the "Basic Traditional Chinese Medicine" course in 2018 and 2019 ( $n=80$ and $n=77$, respectively, for a total of $157)$ were enrolled in this study. Informed consent and a voluntary questionnaire were administered to the participants during the last class.

\section{Course design and teaching methods}

The "Basic Traditional Chinese Medicine" course is provided in the second academic year (in the preclinical phase) of the six-year MBBS program. It covers 32 lessons, for a total of 1440 mins completed in eight teaching weeks, including 24 theoretical lessons and 8 practical lessons. The theoretical lessons consist of six parts: an introduction to TCM and traditional Chinese philosophy; TCM etiology and pathomechanism; TCM diagnostics; TCM therapeutic principles and methods; TCM life nurturing; and modern research on TCM. The practical lessons are interspersed and coordinated with theoretical lessons and are designed to help the students practice the skills of acupuncture, moxibustion, massage, cupping, the identification of Chinese herbs, the four diagnostic methods of TCM, and TCM methods of life nurturing such as Taiji. Beyond the 32 lessons, the course also includes clinical practice at the Department of Chinese Integrative Medicine, Women's Hospital, School of Medicine, Zhejiang University, China. The course employs various teaching methods, including LBL, flipped classroom, problem-based learning (PBL), team-based learning (TBL), case-based learning (CBL), 
skill practice, experiential teaching and visualized teaching. One noticeable feature is the application of the flipped classroom. In brief, teachers determine the learning arrangements and lecture about theoretical knowledge, while students are divided into groups and encouraged to watch videos or consult literature beyond the class boundaries to consolidate or self-learn TCMrelated knowledge. The classroom then becomes a place where presentations and discussions are performed by students for half the class time. Interaction is increased by the use of the question-and-answer mode between teachers and students. Students are graded in light of their attendance, class assignments, class presentation and final essays.

\section{Data collection}

An anonymous, self-administered questionnaire (shown as Additional file 1) was handed out during the last theoretical lesson, which was also the last lesson of the course. Since there is no recognized authoritative questionnaire on TCM learning assessment, we designed the questionnaire according to the objective of the study. Prior to distribution, the questionnaire was sent to several TCM educators and students to determine its validity and consistency. The questionnaire comprised 21 questions, including 3 demographic data questions about the student's age, gender and country of origin, and 18 close-ended questions consisting of 9 single choice and 9 multiple choice. The 9 single-choice questions aimed to investigate students' self-reported evaluation of their knowledge, interest, understanding, benefits and satisfaction with TCM learning. Each question used a 4-point Likert scale, where 1 was 'strongly disagree', 2 was 'disagree', 3 was 'agree' and 4 was 'strongly agree'. Then, we obtained a score for each question. The 9 multiplechoice questions aimed to investigate detailed information on the students' opinions about the TCM courses, such as the course content and teaching methods. The students who agreed to participate in the study completed and returned the questionnaire. The average time needed to complete the questionnaire was 5 mins.

\section{Statistical analysis}

The results of the questionnaire were entered and translated into digital format using Microsoft Office Excel Version 2011 (Microsoft Corporation, Redmond, Washington). Statistical analysis was performed using IBM SPSS (IBM Corp. Released 2012. IBM SPSS Statistics for Windows, Version 21.0. Armonk, NY: IBM Corp.). Descriptive information for variables was provided as the mean \pm standard deviation (SD) or $\mathrm{n}(\%)$, according to the nature of the variable. Variables were compared using one-way analysis of variance (ANOVA) at a statistical significance level of 0.05 .

\section{Results}

Response rate and demographic characteristics

A total of 133 students responded to the questionnaire out of the 157 students who were enrolled in the "Basic Traditional Chinese Medicine" course during the 2018 and 2019 academic years. The response rate was $84.7 \%$. The number of respondents for each question of the questionnaire is shown in Fig. 1. Among the participants, $52(39.1 \%)$ were males and 81 (60.9\%) were females. The response rate was higher among female students (92 students, 88.0\%) than male students (65 students, $80.0 \%)$. In regard to the country of origin, 112 out of 133 students responded. Among the respondents, 96 students $(85.7 \%)$ were from Asian countries, and the top five countries with large student populations were India 33 (29.5\%), Thailand 27 (24.1\%), Iraq 5 (4.5\%), Bahrain 5 (4.5\%) and Indonesia 5 (4.5\%). The distribution of students by country of origin is shown in Table 1 . The average age of the students (125 out of 133 students responded) was $21.90 \pm 2.00$ years old.

\section{Students' self-reported evaluation of learning TCM}

As shown in Table 2, among the respondents, $21.0 \%$ had some prior TCM-related knowledge, and $51.1 \%$ were interested in learning TCM before the course. Most students $(84.1 \%$ of respondents) were able to follow the course content easily during the course. After the course finished, the percentage of students who agreed to have an improved perception, interest and understanding of TCM was 76.5, 66.7 and $61.4 \%$, respectively. Moreover, $77.2 \%$ of students agreed that the course had brought about many benefits (score: $3.05 \pm 0.57$ ), $86.4 \%$ were satisfied with the course content (score: $3.30 \pm 0.49$ ), and $77.3 \%$ were satisfied with the teaching method (score: $3.20 \pm 0.71$ ) of the course.

As most students were from Asian countries, with India and Thailand being in the majority, the mean score of the self-reported evaluations of students from India, Thailand, other Asian countries and non-Asian countries were compared (shown in Table 3). The students from Thailand were significantly more interested in studying TCM than the students from other Asian countries, including India $(p=0.025)$.

\section{Reliability analysis of the questionnaire}

We assessed the validity of 7 single-choice questions from the questionnaire that focused on the students' self-reported evaluations of the TCM course. As shown in Table 4, the reliability coefficient (the value of Cronbach's $\alpha$ ) was 0.826 , indicating that this subscale of the questionnaire (7 items) had good internal consistency. The Cronbach's $\alpha$ values measured in 2018 and 2019 were both higher than 0.8 , indicating that the reliability was stable across time. 

A total of 157 international students attended the course of
"Basic Traditional Chinese Medicine" in the 2018 and 2019
academic years.

All students finished the 32-lessions course, and a self-reported questionnaire was administered to everyone in the last lesson.

133 students responded the questionnaire.

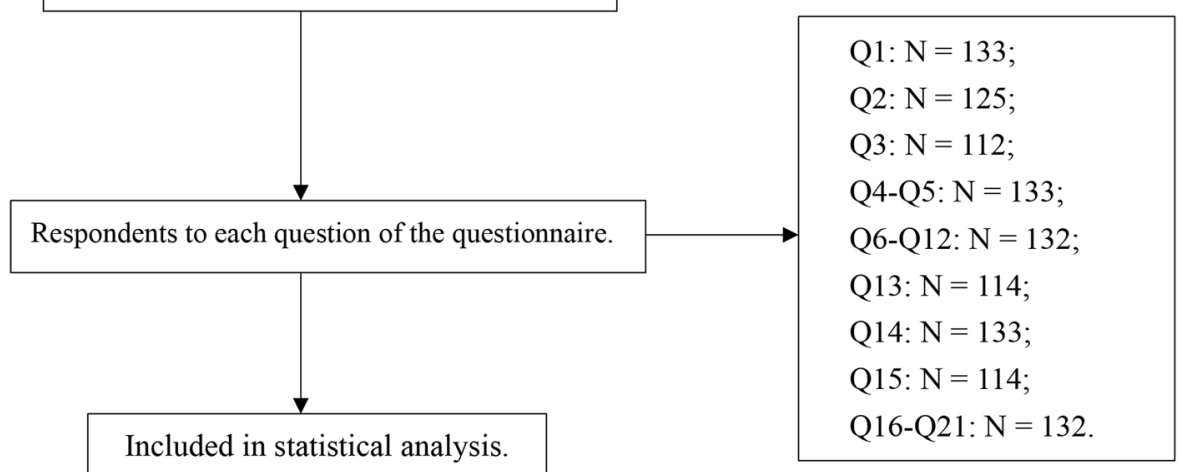

Fig. 1 Flowchart of data collection and analysis

Table 1 Distribution of international students by country of origin $(n=112)$

\begin{tabular}{lll}
\hline Country & Number & Percentage \\
\hline India & 33 & $29.5 \%$ \\
Thailand & 27 & $24.1 \%$ \\
Iraq & 5 & $4.5 \%$ \\
Bahrain & 5 & $4.5 \%$ \\
Indonesia & 5 & $4.5 \%$ \\
Syria & 4 & $3.6 \%$ \\
Malaysia & 3 & $2.7 \%$ \\
England & 3 & $2.7 \%$ \\
Sudan & 2 & $1.8 \%$ \\
Yemen & 2 & $1.8 \%$ \\
Singapore & 2 & $1.8 \%$ \\
Australia & 2 & $1.8 \%$ \\
Iran & 2 & $1.8 \%$ \\
Others & 17 & $15.2 \%$
\end{tabular}

${ }^{a}$ Only 1 student for each country, i.e., Afghanistan, Bangladesh, Egypt, Germany

Ghana, Jamaica, Kazakhstan, Kenya, Kuwait, Pakistan, Russia, Rwanda, South Africa, Sri Lanka, United Arab Emirates, United States, and Zimbabwe

\section{Detailed information on students' opinions about the TCM course}

Before the course, 50.9 and $43.9 \%$ of the students' impressions of TCM were focused on its practicability and mysterious nature, respectively (Fig. 2a); 63.9 and $51.9 \%$ of students had more knowledge about acupuncture and moxibustion and the basic theory of TCM, respectively (Fig. 2b); and $63.2 \%$ were most interested in acupuncture and moxibustion (Fig. 2c). After the course finished, 40.9, 37.9, and 34.9\% of the students had altered their perception of TCM diagnosis, the basic theory of TCM, and life nurturing, respectively (Fig. 2d). In particular, 50.8\% had a deeper understanding of the basic theory of TCM (Fig. 2e). Moreover, $52.3 \%$ of the students had improved their level of interest in regard to learning acupuncture and moxibustion (Fig. 2f); 52.3 and $40.9 \%$ of students wanted to continue their study of acupuncture and moxibustion and TCM diagnoses, respectively (Fig. $2 \mathrm{~g}$ ). In addition, 67.4 and $59.1 \%$ of the students wanted to engage in more skill practices primarily for acupuncture and moxibustion and for massage and cupping, respectively (Fig. 2h). Regarding the preferred teaching methods, 59.1, 56.8, and $48.5 \%$ of the students suggested the implementation of more skilled practice, live demonstrations and videos, respectively (Fig. 2i). 
Table 2 Students' self-reported evaluations about learning TCM

\begin{tabular}{|c|c|c|c|c|c|}
\hline \multirow[t]{2}{*}{ Items } & \multicolumn{4}{|l|}{ Proportion, N (\%) } & \multirow{2}{*}{$\begin{array}{l}\text { Score }^{a}, \\
\text { mean } \pm \text { SD }\end{array}$} \\
\hline & Strongly disagree & Disagree & Agree & Strongly agree & \\
\hline \multicolumn{6}{|l|}{ Evaluation of learning background } \\
\hline Before the course, you had some TCM-related knowledge. ( $N=133)$ & $26(19.5)$ & $79(59.4)$ & $24(18.0)$ & $4(3.0)$ & $2.05 \pm 0.71$ \\
\hline Before the course, you were interested in learning TCM. $(N=133)$ & $18(13.5)$ & $47(35.3)$ & $47(35.3)$ & $21(15.8)$ & $2.53 \pm 0.92$ \\
\hline \multicolumn{6}{|l|}{ Evaluation of the TCM learning course } \\
\hline You have understood well the content of the course. $(N=132)$ & $2(1.5)$ & $19(14.4)$ & $84(63.6)$ & $27(20.5)$ & $3.03 \pm 0.64$ \\
\hline You have altered your perception of TCM. $(N=132)$ & $4(3.0)$ & $27(20.5)$ & $75(56.8)$ & $26(19.7)$ & $2.93 \pm 0.72$ \\
\hline The course has improved your interest in TCM. $(N=132)$ & $3(2.3)$ & $41(31.1)$ & $52(39.4)$ & $36(27.3)$ & $2.92 \pm 0.82$ \\
\hline You have a deeper understanding of TCM than before. $(\mathrm{N}=132)$ & $6(4.5)$ & $45(34.1)$ & $69(52.3)$ & $12(9.1)$ & $2.66 \pm 0.71$ \\
\hline The course brought you many benefits. $(N=132)$ & $2(1.5)$ & $28(21.2)$ & $63(47.7)$ & $39(29.5)$ & $3.05 \pm 0.76$ \\
\hline You are satisfied with the content of the course. $(N=132)$ & $0(0.0)$ & $18(13.6)$ & $57(43.2)$ & $57(43.2)$ & $3.30 \pm 0.70$ \\
\hline You are satisfied with the teaching methods of the course. $(N=132)$ & $3(2.3)$ & $27(20.5)$ & $42(31.8)$ & $60(45.5)$ & $3.20 \pm 0.85$ \\
\hline
\end{tabular}

${ }^{a}$ The score was obtained by a 4-point Likert scale, where $1=$ strongly disagree, $2=$ disagree, $3=$ agree, $4=$ strongly agree. TCM traditional Chinese medicine

\section{Discussion}

In this study, even though the undergraduate international students we surveyed were majoring in conventional medicine, a few students had basic prior knowledge of TCM, and half of them showed interest in TCM. After taking the TCM course, the majority of students agreed that the course had improved their interest, perception and understanding toward TCM, and they were satisfied with the course content and the teaching method. Students also expressed their willingness to further study acupuncture and obtain more skill practices in regard to acupuncture. Suggestions from students regarding the teaching methods included more skilled practice and more visualized learning methods.
TCM has gained increasing acceptance and popularity within the global community because of its alignment with biomedical models of professionalization, education, research and practice $[6,16]$. Among the conventional health professions, acupuncture is a popular modality of complementary medicine, for example for chronic pain [17], although it could vary among settings, like clinical psychologists who would prefer to learn other complementary medicines [18]. Moreover, acupuncture is the only therapeutic method of TCM that the World Health Organization has identified for its effectiveness for numerous diseases [19], and it is the main field for modern research on TCM in countries other than China [20]. In such an international environment, it is no wonder that international students have at least

Table 3 Self-reported evaluations of students from different regions about learning TCM

\begin{tabular}{|c|c|c|c|c|c|c|}
\hline Items & $\begin{array}{l}\text { Thailand } \\
(N=27)\end{array}$ & $\begin{array}{l}\text { India } \\
(N=33)\end{array}$ & $\begin{array}{l}\text { Other Asian countries } \\
(N=36)\end{array}$ & $\begin{array}{l}\text { Non-Asian countries } \\
(N=16)\end{array}$ & $F$ & $p$ \\
\hline \multicolumn{7}{|l|}{ Evaluation of learning background } \\
\hline $\begin{array}{l}\text { Before the course, you had some TCM-related } \\
\text { knowledge. }\end{array}$ & $2.11 \pm 0.70$ & $1.94 \pm 0.70$ & $2.06 \pm 0.80$ & $2.00 \pm 0.52$ & 0.321 & 0.810 \\
\hline $\begin{array}{l}\text { Before the course, you were interested in } \\
\text { learning TCM. }\end{array}$ & $3.00 \pm 0.79$ & $2.48 \pm 0.80^{*}$ & $2.33 \pm 0.96^{* *}$ & $2.56 \pm 0.89$ & 3.255 & 0.025 \\
\hline \multicolumn{7}{|l|}{ Evaluation of the TCM learning course } \\
\hline $\begin{array}{l}\text { You have understood well the content of } \\
\text { the course. }\end{array}$ & $3.00 \pm 0.73$ & $3.03 \pm 0.73$ & $3.06 \pm 0.53$ & $2.94 \pm 0.68$ & 0.127 & 0.944 \\
\hline You have altered your perception of TCM. & $3.00 \pm 0.68$ & $2.94 \pm 0.76$ & $2.92 \pm 0.81$ & $2.75 \pm 0.78$ & 0.373 & 0.772 \\
\hline The course has improved your interest in TCM. & $3.15 \pm 0.82$ & $2.88 \pm 0.83$ & $2.89 \pm 0.71$ & $2.81 \pm 0.91$ & 0.858 & 0.465 \\
\hline $\begin{array}{l}\text { You have a deeper understanding of TCM } \\
\text { than before. }\end{array}$ & $2.63 \pm 0.79$ & $2.59 \pm 0.71$ & $2.64 \pm 0.68$ & $2.81 \pm 0.66$ & 0.351 & 0.788 \\
\hline The course brought you many benefits. & $3.33 \pm 0.83$ & $3.15 \pm 0.76$ & $2.97 \pm 0.61$ & $2.81 \pm 0.91$ & 2.017 & 0.116 \\
\hline You are satisfied with the content of the course. & $3.48 \pm 0.64$ & $3.36 \pm 0.65$ & $3.28 \pm 0.70$ & $3.19 \pm 0.75$ & 0.770 & 0.513 \\
\hline $\begin{array}{l}\text { You are satisfied with the teaching methods } \\
\text { of the course. }\end{array}$ & $3.33 \pm 0.78$ & $3.33 \pm 0.74$ & $3.19 \pm 0.92$ & $2.94 \pm 1.00$ & 0.949 & 0.420 \\
\hline
\end{tabular}

Data are presented as the mean $\pm \mathrm{SD} .{ }^{*} P<0.05,{ }^{* *} P<0.01$ compared with students from Thailand by one-way ANOVA. TCM traditional Chinese medicine 
Table 4 Reliability analysis of the subscale of the questionnaire

\begin{tabular}{llll}
\hline Year & $\mathbf{N}$ of observed values & $\mathbf{N}$ of items & Cronbach $\boldsymbol{a}$ \\
\hline 2018 & 68 & 7 & 0.820 \\
2019 & 63 & 7 & 0.838 \\
Total & 131 & 7 & 0.826 \\
\hline
\end{tabular}

a basic prior knowledge of TCM, mainly pertaining to acupuncture. The survey also showed that international students' interest in learning TCM was mainly in relation to acupuncture and that they desired further study in regard to both fundamental theory and the skilled practice of acupuncture. Thus, in addition to satisfying the interest of international students in regard to learning acupuncture, TCM education should also emphasize the basic TCM theories, diagnostics and herbal remedies, as TCM comprises a whole system of medicine. Additionally, to alter the impression of foreign students that TCM is a "mystery", the issue of how we can infuse evidence-based medicine into current TCM education and practice should be considered [21].

The respondents of this questionnaire-based study were mainly from Asia, among which more were from India and Thailand than from other countries. As students come from different ethnic groups and nations with a variety of cultural backgrounds and modes of thought [11], they have different perspectives and attitudes toward learning TCM. The students from Thailand showed more interest in learning TCM than did those from other Asian countries, which may be induced by the rapid spread and development of TCM in Thailand. In 2000, Thailand became the first country

A Before the course, what was your impression of $T C M$ ? $(\mathrm{N}=114)$
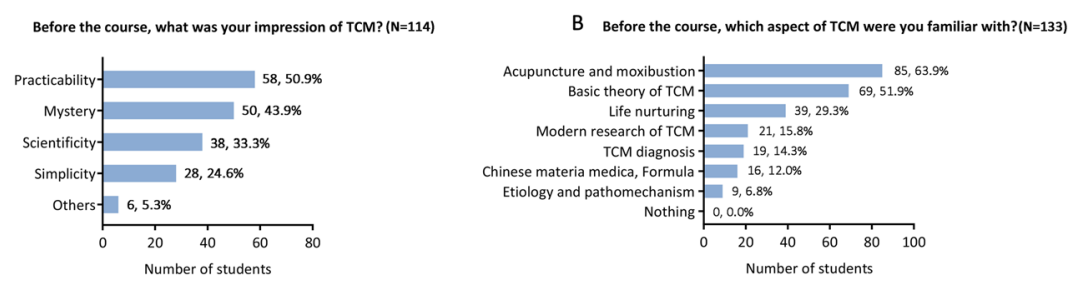

C Before the course, which aspect of TCM were your interested in? (N=114)
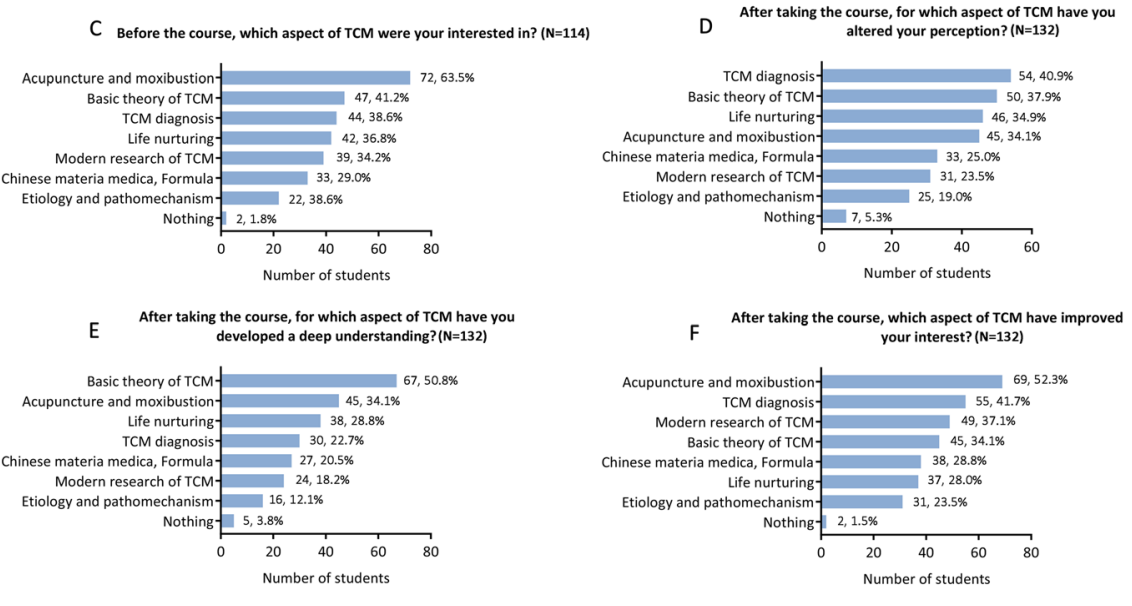

H For which aspect of TCM do you want to obtain more skilled? ( $N=132$ )
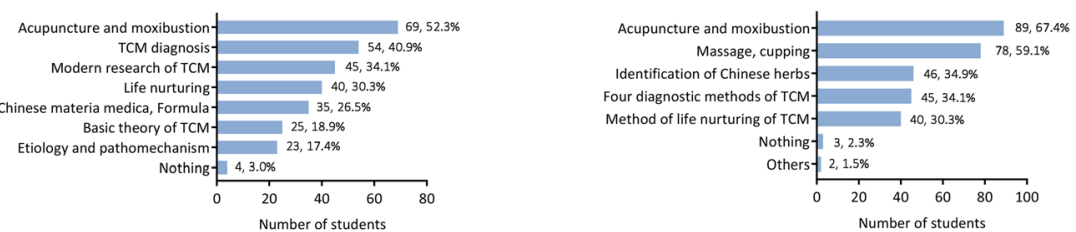

Massage, cupping-

$\begin{array}{rr}\text { Identification of Chinese herbs } \\ \text { Four diagnostic methods of TCM- }\end{array} \quad 46,34.9 \%$

Method of life nurturing of TCM-

$$
\begin{aligned}
& \text { Nothing-1 } 3,2.3 \%
\end{aligned}
$$

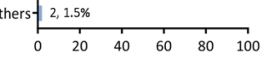

For which learning methods do you suggest can be more frequently

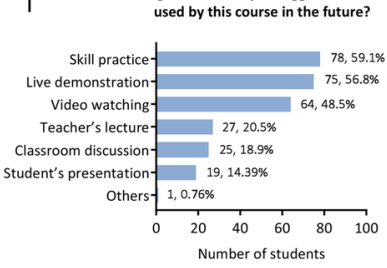

Fig. 2 Detailed information of students' opinions about the TCM course. TCM, traditional Chinese medicine 
outside of China to legalize the practice of TCM [22]. Since 2003, higher education institutions in Thailand have developed partnerships with many TCM medical universities in China [23]. In 2016, the Confucius Institute of TCM was established in Thailand and has made great contributions to the spread of TCM [24]. These events in Thailand indicate that international collaboration and exchanges have strong potential in regard to promoting the internationalization of TCM education.

TCM education has been made a mandatory part of the medical education in most medical universities in China. Although challenges are perceived as persisting with regard to TCM education for international students in medical universities or schools in China $[12,25,26]$, efforts to explore appropriate learning models have been made. A transformation from traditional didactics to those with a greater emphasis on PBL and CBL may be a welcomed reform in TCM education [27, 28]. The implementation of the flipped classroom, which integrates the application of online mini-video courses, teamwork, discussion, classroom presentation and a question-andanswer mode, has been put forward by scholars in the TCM education field [29]. In this study, an initial exploration was undertaken to reform the TCM course, which was mainly reflected in the transformation from the conventional teacher-centered LBL method to a studentcentered multiform learning model. One previous study conducted in the medical school of Xi'an Jiaotong University in China surveyed international students' barriers to and interests in learning TCM and collected their suggestions on the TCM curriculum; this study found that TCM education reformation was required and feasible [30]. Another study investigated the teaching effectiveness of multiple teaching methods applied in TCM education at Capital Medical University, a Western medical university in China, and found that the application of $\mathrm{PBL}, \mathrm{CBL}$ and comparative teaching methods could improve students' enthusiasm for learning TCM [28]. The present study was in accordance with the studies from other universities that have found that improving the teaching models is an important measure of reformation in regard to promoting TCM education [28, 30].

When international students were asked about their impression of TCM before the course, $50.9 \%$ agreed that it seemed practicable, and $43.9 \%$ considered it mysterious. A few students ( $21.0 \%$ of the respondents) reported that they had some prior TCM knowledge, and half of them $(51.1 \%$ of the respondents) showed an interest in learning TCM. We investigated whether the course had positive impacts, and the majority of the students selfreported an improved perception, interest and understanding of TCM and that they had obtained benefits from the course. They also expressed satisfaction with the course. However, some students disagreed that the course had improved their interest in and understanding of TCM (33.4 and $38.6 \%$ of respondents, respectively). The reason for this outcome may be because the course is mainly theoretical and the theory of TCM itself is challenging. Moreover, similar to previous reports [1, 31], the international students we surveyed desired more skilled practice and live demonstrations, and acupuncture was the most preferred aspect to be learned and practiced by them. Thus, from the perspective that the attention of TCM education reform should be directed toward students' learning barriers and needs, a better integration of theory and practice could be arranged in the TCM course design. It is also important to strengthen communication and interaction with international students, as well as to make the obscure TCM theories lively and accessible by using multimedia materials [25,32].

This study has several limitations. First, although students from two academic years participated in the study, the sample size was small. The study was conducted at a single university, and the majority of the international students surveyed in this study were from Asian countries; thus, the responses did not reflect all international medical students in China. Second, the validity of the questionnaire has not been fully determined, and the self-administered questionnaire might lead to potential information bias from the participants. Third, we could not recruit a control group for the study due to the feasibility, and we also failed to have a pre- and postevaluation to determine the effects of the educational intervention. Accordingly, in the future, we would consider a pretest/posttest study design on a continuous basis and across a larger sample of students to investigate the effects of the TCM course.

\section{Conclusions}

In conclusion, international undergraduates majoring in conventional medicine in China seem to have a basic prior knowledge of and interest in TCM, especially in regard to acupuncture. The majority of the international students we surveyed agreed that the TCM course improved their interest in and understanding of TCM. They also showed satisfaction with the TCM course, which employed a student-centered, multiform learning model. It is suggested that TCM education reform should be directed toward students' learning barriers and needs.

\section{Supplementary Information}

The online version contains supplementary material available at https://doi. org/10.1186/s12906-020-03174-1.

Additional file 1. Title: Questionnaire for the "Basic Traditional Chinese Medicine" course. Description: Not applicable. 


\section{Abbreviations}

TCM: Traditional Chinese medicine; MBBS: Medical Bachelor, Bachelor of Surgery; ZUSM: Zhejiang University School of Medicine; LBL: Lecture-based learning; PBL: Problem-based learning; TBL: Team-based learning; CBL: Casebased learning

\section{Acknowledgements}

We would like to express our great appreciation to the students who participated in the study.

\section{Authors' contributions}

FQ participated in study design, data interpretation and manuscript review. QZ designed the study, conducted data analysis and wrote the manuscript. MCD, YJH and JQW collected the data and participated of data analysis. XZ, $\mathrm{YHZ}$ and $\mathrm{YEG}$ contributed to designing the questionnaire. FFW and XRX contributed to the course design. All authors read and approved the final manuscript.

\section{Funding}

The work was supported by the Education Reform Research Key Project of Women's Hospital, School of Medicine, Zhejiang University (number ZDFY201803) and the project of Education of Zhejiang Province (Y201942151).

\section{Availability of data and materials}

The dataset supporting the conclusions of this article is available in the Mendeley Data repository, https://doi.org/10.17632/7rdppkyzy2.1

\section{Ethics approval and consent to participate}

This study obtained informed consent from students enrolled in the study. Students completed the questionnaire voluntarily. The work was approved by Zhejiang University (Course code: 72120240). The study protocol and implementation process were approved and supervised by the School of Obstetrics and Gynecology, Zhejiang University School of Medicine.

\section{Consent for publication}

Not applicable.

\section{Competing interests}

The authors declared that they have no competing interests.

\section{Author details}

'Women's Hospital, School of Medicine, Zhejiang University, 1 Xueshi Road, Hangzhou 310006, Zhejiang, China. ${ }^{2}$ The Second Clinical Medical College, Zhejiang Chinese Medical University, Hangzhou 310053, China.

Received: 20 April 2020 Accepted: 2 December 2020

Published online: 07 January 2021

\section{References}

1. Hua M, Fan J, Dong H, Sherer R. Integrating traditional Chinese medicine into Chinese medical education reform: issues and challenges. Int J Med Educ. 2017:8:126-7.

2. Lew HL, Lee J, Chen JL, Chen SC. Complementary and alternative medicine education in the United States, China, and Taiwan. Phys Med Rehabil Clin N Am. 2004;15(4):933-42 viii-ix.

3. Zhang J, Zhu H, Xie Y. Thoughts on the traditional Chinese medicine education in western medical colleges. Chinese J Inf Tradit Chinese Med. 2013;20(11):100

4. Xue $P$, Jian-Ping L. Comparison of chinese medicine higher education programs in China and five western countries. J Altern Complement Med. 2016;22(6):A97.

5. Chen J, Loyeung B, Zaslawski C, Liang FR, Li WH. Comparison of traditional Chinese medicine education between mainland China and Australia-a case study. J Integr Med. 2016;14(4):291-6.

6. Flesch H. A foot in both worlds: education and the transformation of Chinese medicine in the United States. Med Anthropol. 2013;32(1):8-24.

7. Chang Z, Zhang CM, Sun ZX, Wang ZL, Chen JS, Wang Z. Characteristics of Chinese medicine education under British education system in New Zealand. Chin J Integr Med. 2019;25(12):936-8.
8. Du HB. Traditional Chinese medicine education in Canada. Chin J Integr Med. 2015;21(3):173-5.

9. Fan A, Kosik R, Chen Q. Internationalisation of Chinese medical schools. Lancet. 2013;381(9882):1984.

10. Introduction to MBBS program. http://www.cmm.zju.edu.cn/cmmenglish/2 019/0328/c32038a1615405/page.htm. Accessed 1 Jan 2020.

11. Lü B, Ma F. How to lead foreign students into traditional Chinese medicine. J Med Coll PLA. 2013;28(1):39-45.

12. Sun L, LIU Y. Analysis on the traditional Chinese medicine education in western medical colleges and universities and reflection on existing problems. Lishizhen Med Mater Med Res. 2016;27(5):1240-1.

13. China University Rankings 2020 (Mainland). http://www.cnur.com/ChinaUniversity-Rankings-2020. Accessed 13 Aug 2020.

14. QS World University Rankings 2020. https://www.qs.com/portfolio-items/ world-university-rankings-2020/. Accessed 13 Aug 2020.

15. Zhejiang University School of Medicine. http://www.cmm.zju.edu.cn/ cmmenglish/32023/list.htm. Accessed 1 Jan 2020.

16. World Health Organization. WHO traditiona Imedicine strategy: 2014-2023. http://apps.who.int/iris/bitstream/10665/92455/1/9789241506090_eng. pdf?ua=1. Accessed 1 Jan 2020.

17. Aveni E, Bauer B, Ramelet AS, Kottelat Y, Decosterd I, Finti G, Ballabeni P, Bonvin E, Rodondi PY. The attitudes of physicians, nurses, physical therapists, and midwives toward complementary medicine for chronic pain: a survey at an academic hospital. Explore (NY). 2016;12(5):341-6.

18. Liem A, Newcombe PA. Development of complementary and alternative medicine (CAM) education for clinical psychologists: an example from Indonesia. Int J Ment Health. 2020;49(1):17-34.

19. World Health Organization. Acupuncture: review and analysis of reports on controlled clinical trials. http://apps.who.int/medicinedocs/pdf/s4926e/s4926 e.pdf .Accessed 1 Jan 2020.

20. Jiang J, Peng W, Gu T, King C, Yin JK. Critical review of data evaluation in teaching clinics of traditional Chinese medicine outside China: implications for education. Explore (NY). 2016;12(3):188-95.

21. Kwon $Y$. Chinese medicine education and its challenges in the United States. Chin J Integr Med. 2014;20(4):256-62.

22. Zeng Q, Sun XS. Overview of academic education of Traditional Chinese Medicine in Thai. Chin Med Cult. 2018;13(03):86-92.

23. Xie $Q, X u Y, L i ~ M, X u L$. Development of traditional Chinese medicine education in Thailand. Tianjin J Tradit Chinese Med. 2015;32(7):442-4.

24. Xiong $S$, Xing Y. Analysis on the spread and development of traditional Chinese medicine in Thailand. Glob Tradit Chinese Med. 2019;12(3):404-7.

25. Zhang Y, Li X. Preliminary study on the problems and solutions of the full English teaching of traditional Chinese medicine for foreign students in western medical university. Chinese Med Modern Distance Educ China. 2019;17(9):140-1.

26. Wang Y, Huang G, Zhang M, Liu Y. Problems and thoughts on TCM teaching in English for the international students in our universities. Res Integr Tradit Chinese Western Med. 2013;5(1):53-4.

27. Chen J, Li Y, Tang Y, Zeng F, Wu X, Liang F. Case-based learning in education of traditional Chinese medicine: a systematic review. J Tradit Chin Med. 2013;33(5):692-7.

28. Fan Y, Liu Y. Exploration of multiple teaching methods to improve the teaching effect of traditional Chinese medicine. Med Educ Manage. 2017; 3(z2):47-50.

29. Liu Q, Ling J, Huang L. An idea of practicing the flipped classroom in the education of Traditional Chinese medicine for the foreign students in the western medical universities. Chinese Med Modern Distance Educ China. 2016;14(24):10-2.

30. Liu Y, Cai Y, Sun Y, Han P, Zhang Z, Wang R. Explorat ion on the Educat ion reform of traditional Chinese medicine for foreign students in Western Medical University based on questionnaire survey. Chinese Med Modern Distance Educ China. 2016;14(4):31-2.

31. Lu K, Du W, Xia Q, Xu W. Discussion on TCM education for foreign students in Western Medical University. China Contin Med Educ. 2019;11(17):54-5.

32. Su W, Yuan W, Li G, Li J, Li C. Exploration on TCM education for the foreign students of clinical medicine Department in Western Medicine University. World J Integr Tradit Western Med. 2015;10(02):250-1.

\section{Publisher's Note}

Springer Nature remains neutral with regard to jurisdictional claims in published maps and institutional affiliations. 